\title{
RESULTS OF STUDY OF SULFUR OXIDE REDUCTION DURING COMBUSTION OF COAL- WATER SLURRY FUEL THROUGH USE OF SULFUR CAPTURING AGENTS
}

\author{
Vasiliy I. Murko ${ }^{1}$, Viktor I. Karpenok ${ }^{1}$, Yuliya A. Senchurova ${ }^{1}$, Oleg V. Tailakov ${ }^{1}$, \\ Alexander R. Bogomolov, ${ }^{2}$, and Veniamin A. Khyamyalyainen ${ }^{1}$ \\ ${ }^{1}$ Kuzbass State Technical University named after T.F. Gorbachev, 650000 Kemerovo, Russia \\ ${ }^{2}$ Kutateladze Institute of Thermophysics SB RAS, 630090 Novosibirsk, Russia
}

\begin{abstract}
It is shown that an effective way of burning high sulfur coal is to burn coal-water slurry fuel (CWF) prepared on its basis containing a sulfur capture agent (SCA) entered in the slurry at the stage of preparation. The technique of thermodynamic analysis of chemical reactions during CWF burning has been developed including burning in the presence of SCA. Using the developed calculation program, the optimal temperature conditions have been determined as required for the effective reduction of sulfur oxides in flue gases when using different types of SCA. According to the results of calculating the composition of CWF combustion products when entering various substances in the burner space as SCA it has been determined that magnesite, calcite, and dolomite are the most effective natural minerals. The analysis of calculated and experimental data proves the efficiency of SCA addition as well as validity of the obtained results.
\end{abstract}

\section{Introduction}

It is known $[1,2]$ that addition of SCA in the fuel or feed of SCA directly in the combustion area is one of the effective methods of reducing the content of sulfur oxides in flue gases produced by combustion of various fuels, including coal, containing sulfur. When using the first option of sulfur capture it is preferable to use ecologically clean water-coal slurry fuel as coal fuel which already contains sulfur capture agent added at the stage of fuel preparation.

The main point of the second option of sulfur capture (addition of SCA in fuel combustion zone) is that certain chemical elements present in the SCA interacting with sulfur or sulfur-containing substances formed in the combustion process chemically interact to form new solid phase sulfur compounds. In this process a part of the resulting solidphase sulfur compounds falls in the slag funnel of the boiler and is removed from the boiler with the boiler ash and slag, while the remaining part is carried out of the boiler with the flue gases in the form of fines and is captured by the gas treatment system. It is possible to

* Corresponding author: barom $@$ mail.kuzstu.ru 
evaluate the effectiveness of SCA elements impact on sulfur binding process during combustion of different types of coal fuel with the use of chemical thermodynamics methods. With regard to the chemical reactions occurring in the area of coal fuel combustion, it can be argued that subject to environmental conditions (pressure, temperature, composition of substance in the system) corresponding to the equilibrium state and sufficient time for such an interaction, the chemical response of substances located in the furnace space will provide the required (estimated) composition of combustion products. The required time of the reactive agents staying during combustion of various types of coal fuel is provided by rational choice of combustion technology and management of the combustion process.

Recently, swirl method of coal fuels combustion has become widely spread, including fuels significantly filled with water or mineral components [3, 4]. This method provides good mixing of combustion air and fuel, their rapid heating and thereby substantially uniform reactants distribution on the combustion chamber.

It is known [5] that in the chemical thermodynamics finding of conditions ensuring the reduction of the system to an equilibrium state is equivalent to the definition of the system parameters characterizing it when it reaches the state of equilibrium. It is necessary with the use of thermodynamic analysis to determine the chemical composition of this mixture and process conditions in the presence of SCA in which the equilibrium state of the system is achieved. Thus in the system in addition to conventional gaseous substances formed during combustion of wet coal fuel - carbon dioxide, water vapor, and solid ash and slag forming substances, there must be solids containing sulfur present and there should be no gaseous sulfur oxides. As a consequence, it is possible to obtain a complete binding of sulfur in the composition of solids, capture and removal of the latter from the process presents no particular technical difficulties. The results of the thermodynamic analysis need to be confirmed by the results of field experiments.

As van't Hoff has shown [5], as a measure of the chemical affinity, that is as a criterion indicating the direction of the chemical reaction, it should be Helmholtz potential for processes occurring at constant volume and Gibbs energy for processes occurring at constant pressure. We believe that the combustion process in the swirl furnace flows at constant pressure. In view of this in order to find the conditions sought by the system, it is necessary to define minimum isobaric potential (Gibbs free energy).

By definition $Z$ Gibbs energy is a function of the following type:

$$
Z=H-T S,
$$

where $H$ and $S$ - enthalpy and entropy in the operating conditions respectively calculated according to the formulas:

$$
H=H^{0}+\int C_{p} d T ; S=S^{0}+\int\left(C_{p} / T\right) d T,
$$

$H^{0}, S^{0}$ - enthalpy and entropy in the standard conditions respectively, $C_{p}$ - specific heat at constant pressure; $T$ - temperature.

Gibbs potential has a property of additivity, i.e.

$$
Z=\sum Z_{i}
$$

where $Z_{i}$ - Gibbs energy of the i-th substance (component) in the system.

It is obvious that due to the additivity we have:

$$
Z_{i}=Z_{i s v} a_{i},
$$


where $Z_{i s v}$ - specific value of the Gibbs energy of the $\mathrm{i}$-th substance (based on $1 \mathrm{~mol}$ ), $a_{i}-$ quantity of the $i$-th substance, mol.

Thus, solution of the objective to study the furnace process in the physical sense comes to determination of the composition of the system (such a set of substances that makes up the system ) and the temperature at which the Gibbs energy has a minimum value taking into account implementation of the laws of conservation of matter and energy. Therefore from the mathematical point of view it is necessary to find the minimum of a function of many variables:

$$
Z=\sum a_{i}\left(H_{i}^{0}+\int C_{p i} d T-T\left(S_{i}^{0}+\int\left(C_{p i} / T\right) d T\right)\right)
$$

with the additional conditions (restrictions) complying also with the corresponding laws of conservation of matter and energy.

\section{Result and discussion}

As can be seen from equation (1), Z function is linear relative to quantities of substances, but non-linear with respect to temperature. The temperature is as a member of the equation as are the amounts of combustion products, that is the temperature developed in the process of combustion depends on the conditions in the furnace, namely on the quality of the fuel, the balance of fuel and oxidant, heating (or cooling) of the fuel, and the blast air prior to feeding to the furnace. Thus, if we take the temperature in the equation (1) fixed, the problem is reduced to the problem of linear programming, the solution of which is the essence of the thermodynamic analysis. With this in mind, the programme was developed which allows to perform thermodynamic analysis of coal fuel combustion in the presence of SCA. The calculation algorithm is shown in fig. 1.

Combustion processes that take place in the furnace cause redistribution of the elements. For example, oxygen from air passes into carbon dioxide in flue gases. As a result of chemical transformation, the temperature of the system changes. However, the enthalpy of the system (adiabatic condition of the process) and the number of elements (the law of conservation of mass) remain unchanged; substances are transformed from ones into others, but there appear no additional atoms of any new elements. The values of amounts of each element are set in moles as initial data. This is necessary for drawing up of the equations of conservation of matter. The condition of conservation of the enthalpy of the system is taken into account as follows. Each cycle of calculation is carried out at a certain temperature. Throughout the cycle, the temperature is considered constant. Upon completion of the cycle enthalpy of the system is calculated. If the enthalpy is higher than the initial enthalpy of system, the temperature value is reduced, or increased, if otherwise. Next, the cycle of calculation is repeated with the changed temperature value. The calculation is carried out as long as the modulus of difference between the calculated and the initial values of the system enthalpy is less than the predetermined tolerance. In this case, the result of the last cycle is taken as the calculated composition of the combustion products, and the temperature corresponding to the given cycle as the temperature of combustion. In order to achieve a certain temperature in the calculation, the enthalpy of the system should be changed accordingly.

The calculation results using various SCAs showed that:

- in using slaked lime $\left(\mathrm{Ca}(\mathrm{OH})_{2}\right)$ as SCA, effective sulfur capturing is observed at temperature up to $900^{\circ} \mathrm{C}$ and at higher temperatures sulfur capturing efficiency decreases, and $\mathrm{SO}_{2}$ appears in combustion products; 
- in using limestone $\left(\mathrm{CaCO}_{3}\right)$, effective sulfur capturing is observed at temperature up to $1100^{\circ} \mathrm{C}$, and at higher temperatures sulfur dioxide appears in gases;

- in using magnesite $\left(\mathrm{MgCO}_{3}\right)$, effective sulfur capturing is observed at temperature up to $1100^{\circ} \mathrm{C}$, and at higher temperatures sulfur dioxide also appears in the combustion products. It must be noted that magnesium sulfate decomposes at a temperature above $1137^{\circ} \mathrm{C}$, so calculations were performed at temperatures not exceeding $1100^{\circ} \mathrm{C}$;

- in introduction of dolomite (which corresponds to simultaneous introduction of magnesite and calcite) effective sulfur capturing is observed at temperature up to $1100^{\circ} \mathrm{C}$, and at the same time only magnesium dolomite component is "consumed" (which means higher efficiency of magnesite as compared with calcite) and there is an incomplete absorption of sulfur dioxide. Perhaps the presence of magnesium "suppresses" calcium activity, which will be explored experimentally;

- the use of the resulting slag phase $\left(\mathrm{Ca}_{2} \mathrm{SiO}_{4}\right.$ и $\left.\mathrm{CaSiO}_{3}\right)$ is completely ineffective for the purposes of binding sulfur in solid ash and slag compounds. This is likely due to the fact that the slag phase is not a combination of two oxides $\left(\mathrm{CaO}\right.$ and $\left.\mathrm{SiO}_{2}\right)$, but separate chemical compounds. For example, in [6] it is shown that this phase has a higher (by 72 $\mathrm{kJ} / \mathrm{mol}$ ) value of the enthalpy of the formation than the sum of enthalpies of the formation of its constituent oxides, as well as the higher value of the corresponding entropy. Calcium and silicon oxides stirred in the composition of ash at the molecular level form upon combustion conditions the slag phase which is unsuitable as an SCA, and the calculation has shown that.

Thus, introduction of technogenic product (slaked lime) which requires certain costs for its application and is not a natural mineral, was less effective than the use of natural mineral materials - calcite, magnesite, and dolomite.

With regard to magnesite it should be noted that its effective work up to $1100^{\circ} \mathrm{C}$ temperature is attended by some risk since in implementation of the firing process fluctuations (changes) of temperatures are observed quite often, and it is likely that conducting the process "at the upper limit" of SCA ability may from time to time result in appearing of sulfur dioxide in the products.

To assess compliance of the results of calculations and experimental data, the calculation was made corresponding to burning of fuel made from coal of the "Black Sea" mine (Bulgaria) (Table 1).

Table 1. Properties of CWF.

\begin{tabular}{|l|c|c|}
\hline Parameter, symbol & $\begin{array}{c}\text { Unit of } \\
\text { measure }\end{array}$ & \multicolumn{1}{|c|}{ Value } \\
\hline Solid phase content & $\%$ & 50.0 \\
\hline Low calorific value & $\mathrm{kcal} / \mathrm{kg}$ & 2950 \\
\hline Carbon, $\mathrm{C}^{\text {daf }}$ & $\%$ & 72.0 \\
\hline Hydrogen, $\mathrm{H}_{2}{ }^{\text {daf }}$ & $\%$ & 6.0 \\
\hline Nitrogen, $\mathrm{N}_{2}{ }^{\text {daf }}$ & $\%$ & 1.5 \\
\hline Oxygen, $\mathrm{O}_{2}{ }^{\text {daf }}$ & $\%$ & 16.7 \\
\hline Sulfur, $\mathrm{S}^{\text {daf }}$ & $\%$ & \multicolumn{1}{|l}{} \\
& & $\begin{array}{l}\text { Including combustible sulfur (organic and pyritic) - } \\
2.4 ; \\
\text { incombustible (sulphate) }-1.4\end{array}$ \\
\hline Ash on dry basis, $\mathrm{A}^{\mathrm{d}}$ & $\%$ & \multicolumn{2}{|l}{22.2} \\
\hline
\end{tabular}


Initial data input. Set up the chemical composition of the mass to be fed to combustion

Calculate mole composition of substances entering the combustion chamber including elementary fuel composition. mineral composition of its ash part as well as SCA composition

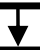

Make substances conservation equations for each of the elements entering the combustion

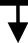

Make a table of values for thermodynamic parameters (standard enthalpy and entropy, heat capacities with consideration of their temperature dependence)

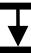

Calculate initial enthalpy of the system, $\Delta H_{0}$

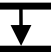

Set up temperature interval within which the thermodynamic study is being made, $T_{\min }, T_{\max }$

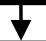

Set up initial temperature which the thermodynamic study is being made, $T_{0}$
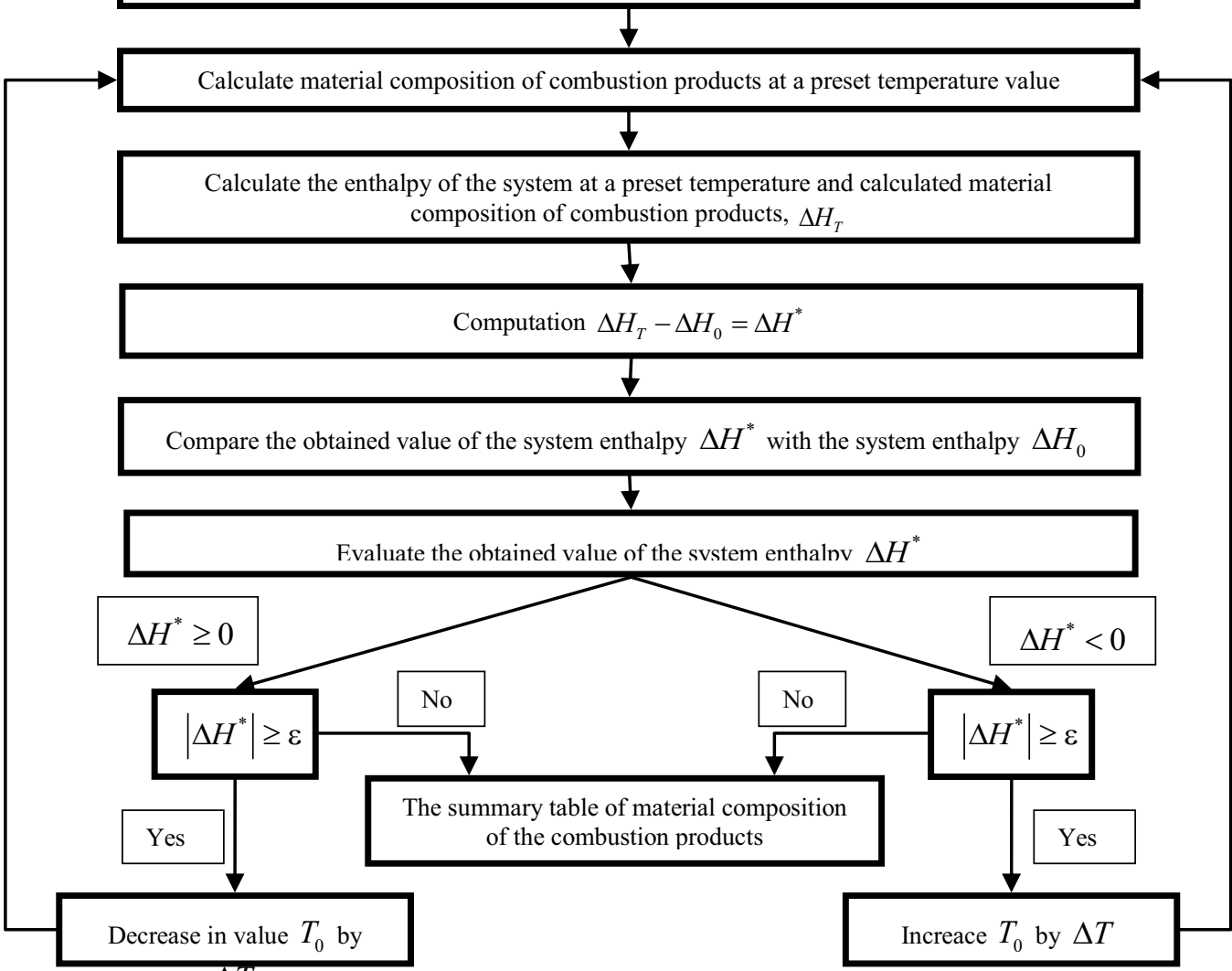

$\Delta T$

Fig. 1. Block diagram for execution of the program of thermodynamic analysis of coal fuel combustion in the presence of SCA. 
Sulfur capture agent was prepared of limestone $\left(46.3 \mathrm{CaO} ; 6.1 \mathrm{MgO} ; 98.1\left(\mathrm{CaCO}_{3}\right.\right.$ $\left.+\mathrm{MgCO}_{3}\right)-\mathrm{GOST}$ 17498-72). Its properties were considered in the initial data for calculation.

The calculations were made for different values of the coefficient of excess air and combustion temperature (Table 2).

Table 2. Calculated composition of CWF combustion products.

\begin{tabular}{|c|c|c|c|c|c|c|c|c|c|}
\hline & \multicolumn{3}{|c|}{$\boldsymbol{\alpha = \mathbf { 0 . 9 }}$} & \multicolumn{3}{c|}{$\boldsymbol{\alpha}=\mathbf{1 . 0}$} & \multicolumn{3}{c|}{$\boldsymbol{\alpha}=\mathbf{1 . 3}$} \\
\cline { 2 - 11 } & $\mathbf{1 1 5 0 K}$ & $\mathbf{1 3 2 0 K}$ & $\mathbf{1 5 5 0 K}$ & $\mathbf{1 1 5 0 K}$ & $\mathbf{1 3 2 0 K}$ & $\mathbf{1 5 5 0 K}$ & $\mathbf{1 1 5 0 K}$ & $\mathbf{1 3 2 0 K}$ & $\mathbf{1 5 5 0 K}$ \\
\hline $\mathrm{C}$ & 0 & 0 & 0 & 0 & 0 & 0 & 0 & 0 & 0 \\
\hline $\mathrm{O}_{2}$ & 0 & 0 & 0 & 0 & 0 & 0 & 3.87 & 3.87 & 3.87 \\
\hline $\mathrm{H}_{2}$ & 5.63 & 0 & 0 & 0 & 0 & 0 & 0 & 0 & 0 \\
\hline $\mathrm{S}$ & 0.19 & 0.19 & 0 & 0.03 & 0.03 & 0 & 0 & 0 & 0 \\
\hline $\mathrm{Mg}$ & 0 & 0 & 0 & 0 & 0 & 0 & 0 & 0 & 0 \\
\hline $\mathrm{Ca}$ & 0 & 0 & 0 & 0 & 0 & 0 & 0 & 0 & 0 \\
\hline $\mathrm{N}_{2}$ & 55.75 & 55.75 & 55.84 & 60.39 & 60.39 & 60.40 & 63.89 & 63.89 & 63.89 \\
\hline $\mathrm{CO}_{2}$ & 15.56 & 9.92 & 9.39 & 13.98 & 13.98 & 13.90 & 11.39 & 11.39 & 11.39 \\
\hline $\mathrm{CO}$ & 0 & 5.63 & 6.19 & 0 & 0 & 0.07 & 0 & 0 & 0 \\
\hline $\mathrm{H}_{2} \mathrm{O}$ & 22.67 & 28.30 & 28.35 & 25.43 & 25.43 & 25.43 & 20.71 & 20.71 & 20.71 \\
\hline $\mathrm{SO}_{2}$ & 0 & 0 & 0.03 & 0 & 0 & 0.027 & 0 & 0 & 0 \\
\hline $\mathrm{SO}_{3}$ & 0 & 0 & 0 & 0 & 0 & 0 & 0 & 0 & 0 \\
\hline $\mathrm{MgO}$ & 0.03 & 0.03 & 0.03 & 0.027 & 0.027 & 0.027 & 0 & 0 & 0 \\
\hline $\mathrm{MgSO}_{4}$ & 0 & 0 & 0 & 0 & 0 & 0 & 0.022 & 0.022 & 0.022 \\
\hline $\mathrm{CaO}$ & 0.16 & 0.16 & 0 & 0.006 & 0.006 & 0 & 0 & 0 & 0 \\
\hline $\mathrm{CaSO}_{4}$ & 0 & 0 & 0.16 & 0.14 & 0.14 & 0.15 & 0.119 & 0.119 & 0.119 \\
\hline
\end{tabular}

As shown in Table 2, a significant impact on the effectiveness of sulfur capture has atmosphere composition in the furnace. In the absence of an excess of oxygen $(\alpha=0.9$ and $\alpha=1.0$ ) elemental sulfur $\mathrm{S}$ is present in the combustion products (at a temperature of up to $1320 \mathrm{~K}$ ) or sulfur dioxide $\mathrm{SO}_{2}$ (at higher temperature values). The magnesium-containing part of SCA is "quiescent". In case of air excess $(\alpha=1.3)$ there was no sulfur or sulfur dioxide over the entire studied temperature range. Sulfur capture agent works fully - in its calcium containing and its magnesium containing part.

For comparison fig. 2 shows the results of calculations and experiments in similar conditions $(\alpha=1.3 ; \mathrm{T}=1750 \mathrm{~K} ; 1320 \mathrm{~K})$.

As is shown in fig. 2, use of SCA leads to almost two-fold reduction of the content of sulfur dioxide in the combustion products. Good agreement between the calculated and experimental values was obtained in burning of CWF without SCA. The calculation with SCA shows complete absence of $\mathrm{SO}_{2}$ in the combustion products while in the experiments the amount of $\mathrm{SO}_{2}$ was respectively 480 and $630 \mathrm{mg} / \mathrm{m}^{3}$ at the combustion temperatures 1340 and $1150 \mathrm{~K}$. The difference between calculated and experimental results is due to the fact that in the experiments it is not possible to sustain the full conditions of physical and mathematical model (in the furnace combustion products stay for a limited time, while the calculation shows the state sought to by the system). Thus, for practical effective removal of sulfur compounds from the flue gas stream it is necessary not only to correctly select an SCA, but also to arrange the combustion process accordingly. Perhaps finalization of design parameters of a furnace unit or working out modes of conducting the combustion process will allow to improve efficiency of SCA application. 


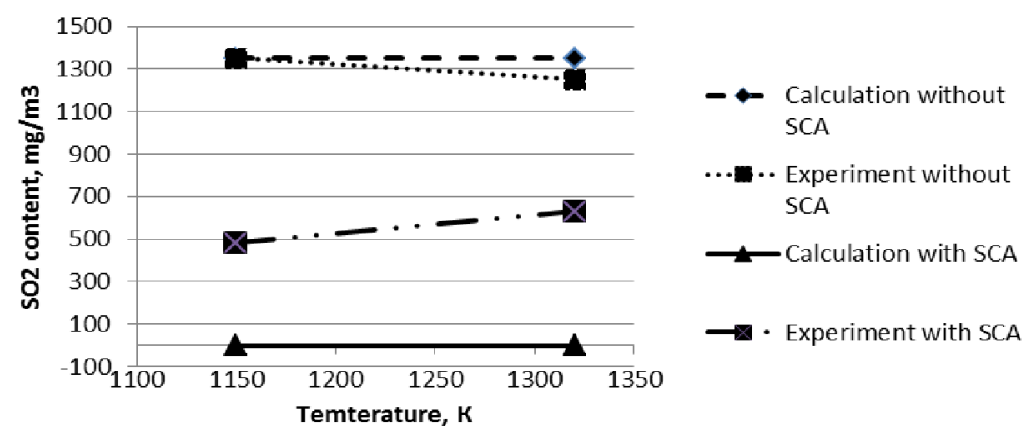

Fig. 2. Comparison of calculated and experimental results of SCA impact on the content of $\mathrm{SO} 2$ in the flue gases from combustion of CWF.

\section{Conclusion}

1. It is shown that the use of technology for preparation and vortex combustion of CWF produced on the basis of high-sulfur coal ensures high efficiency in reduction of sulfur oxides emissions in the flue gases.

2. The method has been developed for thermodynamic analysis of fuel combustion processes including sulfur fuel, in order to determine the effectiveness of performance of various SCAs fed into the combustion area as part of the fuel.

3. Based on the study results the most efficient SCAs were identified as natural minerals - magnesite, calcite, dolomite;

4. The developed method has provided good correlation of the results of calculations and field experiments on the demonstration stand during combustion of high-sulfur Bulgarian coals.

\section{Acknowledgments}

The study has been financially supported by the state in the face of the Minobrnauki of Russia (the Ministry of Education and Science) within the framework of the Federal Targeted Programme of Research and Development in Priority Areas of Russian Scientific and Technological Complex for 2014 to 2020, Agreement No.14.583.21.0004 for a grant of 16 July 2014. The unique identifier of research (project) is RFMEFI58314X0004.

\section{References}

1. Z.R. Ismaguilov, O.V. Tailakov, T.N. Teryaeva et al., Coal 9 (2015)

2. I.Ya. Sigal, Protection of air pool at fuel combustion (Nedra, Leningrad, 1988)

3. Technology of vortex combustion "TORNADO", http://sibpromenergo.ru/boiler/vih/tornado.html

4. V.I. Murko, A.K. Dzhundubaev, M.P. Baranova, A.I. Biybosunov, V.A. Kulagin, Slurry fuel transporting and energy complexes (Russian-Kyrgyz scientific and technical cooperation in the field of power engineering, Krasnoyarsk: Siberian Federal University, 2015)

5. A.N. Krestovnikov, V.N. Vigdorovitch, Chemical thermodynamics (Metallurgy, Moscow, 1973)

6. U.D. Veryatin, V.P. Mashyrev, N.G. Ryabtsev et al., Thermodynamic properties of inorganic substances (Directory. Moscow: Atomizdat, 1965) 